\title{
Re-defining the Future of FOG and Biodiesel
}

\author{
A.M.E. Ragauskas ${ }^{1}$ and A.J. Ragauskas ${ }^{2 *}$
}

${ }^{1}$ Franklin College of Arts and Sciences, University of Georgia, Athens, GA 30602, USA

${ }^{2}$ School of Chemistry and Biochemistry, Georgia Institute of Technology, Atlanta, GA, 30332, USA

The need for secure energy resources has become a dominant theme for most developing and developed nations. In this growing challenge, humankind consumes $87,135,100$ barrels of petroleum/ day that needs to be continuously replaced to ensure our standard of living [1]. Hence, the development of biofuels provides one of the few sustainable solutions to contribute to this challenge. Furthermore, it is also well acknowledged that for the foreseeable future the development of sustainable biofuels needs to be pursued to diminish the net growth of atmospheric carbon. Another benefit for biofuels that is often overlooked is that can provide a viable technical solution for biological based waste materials that maybe difficult to alternatively dispose of in an environmentally compatible, cost-effective manner. For example, transportation ethanol is being recovered from spent brewer's yeasts, waste beer/wine, biodiesel from waste cooking oils and animal rendered fats, and efforts are growing to utilize waste food process streams from citrus and potato processing plants for bioethanol to highlight just a few promising examples.

Another food-related stream that is attracting increasing attention is fats, oils and greases (FOG) generated by restaurant and food products industry and recovered in mandatory grease recovery systems. Most modern building/business codes require the installation of grease traps $(\sim 50 \mathrm{~L})$ or interceptors $(\sim 3785-7570 \mathrm{~L})$ in commercial kitchens and food processing centers [3]. These grease abatement plumbing devices are typically non-mechanical flow-through devices that facilitate the recovery of grease and food solids from an aqueous stream by gravity separation.

Grease Interceptor- A multi-compartment chamber where the grease containing flow is retained long enough so that grease and some solids can rise to the water surface, most of the solids settle to the bottom, and clarified water can eventually be discharged to the sanitary sewer. Interceptors are larger than grease traps and are usually located below ground and outside the food preparation area.

Grease Trap- A grease removal device that is designed to retain a small amount of grease, usually servicing from 1 to 4 plumbing fixtures. Grease traps are usually approved for small dischargers. In some cases, multiple grease traps may be approved by the control authority only when space is not available for a grease interceptor [2].

Indeed, ASME standard A112.14.3 requires that grease inceptors remove a minimum of $90 \%$ of the incoming FOG. The complete pump out of grease interceptors and traps-solids and liquids is now commonly practiced and disposed of at an approved location. The recovered brown grease has been historically land-filled or used for compositing, incineration, or land applications [4]. The Solid Waste Disposal Act prohibits the disposal of bulk liquids like interceptor FOG in landfills [5].

More recently, entrepreneurial/research attention has been directed at using this bioresource for anaerobic digestion to generate bio-gas or utilization as a feedstock for biodiesel. Certainly, the utilization of FOG will only grow in the future since it is a relatively constant volume bioresource which increases with population growth. A recent NREL report estimated that in the U.S.A. FOG is generated at a rate of $7.1 \mathrm{~L}$ FOG/person/year [6]. An examination of the open literature suggests the environmental processing of this waste stream is a global challenge since land filling is increasing in costs and inadvertent discharge of FOG into sewer systems leads to overflows as the FOG solidifies and reduces conveyance capacity and blocks flow. The U.S. EPA has estimated that approximately $23 \%$ of all sanitary sewer overflow events were FOG related and it contributes to $70 \%$ of sewer plant blockages and $30 \%$ of pump station failures [7]. These environmental/economic/public health issues have now encouraged several major metropolitan centers globally to implement FOG control systems, grease trap ordinances and fines for non-compliance.

The advent of the green city movement, persistent high energy costs and need to transition away from food-based biofuels suggests that FOG based biodiesel is an opportunity that will only grow. Especially, in those parts of the global where natural gas costs are low and fuel costs are high the conversion of FOG to biodiesel may be more attractive than biogas. Although the conversion of brown grease to biofuels is technically more difficult than the use of fatty acid trigylcerides, it has its own unique cost advantages. Indeed, several companies are now pursuing this vision by taking FOG brown grease using

(i) An acidic alcohol pretreatment which converts free-fatty acids to their respective esters followed by

(ii) A traditional base-catalyzed alcohol trans-esterification to convert the remaining tri/di/monoglycerides to their corresponding alkyl esters which after purification yields a viable biodiesel resource [8]. Indeed, an examination of patent and research literature indicates a host of researchers are now beginning to recognize these opportunities and improved one-stage chemical/biological systems are being developed to directly convert FOG, with various levels of free fatty acids and substituted glycerides, to biodiesel [9].

In summary, trap/interceptor-FOG is an attractive biodiesel precursor which society is mandating to be collected and processed in an environmentally acceptable manner and this opens the door for entrepreneurs and researchers for a better, greener tomorrow.

\section{References}

1. Oil and Petroleum Products. Environmental Protection Agency.

*Corresponding author: A.J. Ragauskas, School of Chemistry and Biochemistry, Georgia Institute of Technology, Atlanta, GA, 30332, USA, Tel: 404-894-9701; Fax: 404-894-4778; E-mail: arthur.ragauskas@chemistry.gatech.edu

Received December 28, 2012; Accepted December 29, 2012; Published December 31, 2012

Citation: Ragauskas AME, Ragauskas AJ (2013) Re-defining the Future of FOG and Biodiesel. J Pet Environ Biotechnol 4:e118. doi:10.4172/2157-7463.1000e118

Copyright: (c) 2013 Ragauskas AME, et al. This is an open-access article distributed under the terms of the Creative Commons Attribution License, which permits unrestricted use, distribution, and reproduction in any medium, provided the original author and source are credited. 
Citation: Ragauskas AME, Ragauskas AJ (2013) Re-defining the Future of FOG and Biodiesel. J Pet Environ Biotechnol 4:e118. doi:10.4172/2157$7463.1000 \mathrm{e} 118$

2. (2004) A Guide for Developing and Implementing a Fats, Oils, and Grease (FOG). Control Program for Food Service Establishments.

3. Industrial Pretreatment Program. Environmental Protection Agency.

4. Long JH, Aziz TN, Reyes FLDL III, Ducoste JJ (2012) Anaerobic co-digestion of fat, oil, and grease (FOG): a review of gas production and process limitations. Process Safety and Environmental Protection 90: 231-245.

5. Weiss M (2007) Grease Interceptor Facts and Myths, Plumbing Systems \& Design 33-39.
6. Wiltsee G (1998) Urban Waste Grease Resource Assessment.

7. (2004) Characterization of CSOs and SSOs. Environmental Protection Agency EPA, Report to Congress.

8. Montefrio MJ, Tai X, Obbard JP (2010) Recovery and pre-treatment of fats, oi and grease from grease interceptors for biodiesel production. Applied Energy 87: 3155-3161.

9. Hasuntree P, Toomthong V, Yoschoch S, Thawornchaisit U (2011) The potential of restaurant trap grease as biodiesel feedstock. Songklanakarin Journal of Science and Technology 33: 525-530. 